\title{
BMJ Open Danish Observational Study of Eldercare work and musculoskeletal disorderS (DOSES): a prospective study at 20 nursing homes in Denmark
}

\author{
Kristina Karstad, ${ }^{1,2}$ Anette F B Jørgensen, ${ }^{1}$ Birgit A Greiner, ${ }^{3}$ Alex Burdorf, ${ }^{4}$ \\ Karen Søgaard, ${ }^{2,5}$ Reiner Rugulies, ${ }^{1,6,7}$ Andreas Holtermann ${ }^{1,2}$
}

To cite: Karstad K, Jørgensen AFB, Greiner BA, et al. Danish Observational Study of Eldercare work and musculoskeletal disorderS (DOSES): a prospective study at 20 nursing homes in Denmark. BMJ Open 2018;8:e019670. doi:10.1136/ bmjopen-2017-019670

- Prepublication history and additional material for this paper are available online. To view these files, please visit the journal online (http://dx.doi org/10.1136/bmjopen-2017019670).

Received 19 September 2017 Revised 2 January 2018 Accepted 26 January 2018

\section{Check for updates}

${ }^{1}$ National Research Centre for the Working Environment (NRCWE), Copenhagen,

Denmark

${ }^{2}$ Department of Sports Science and Clinical Biomechanics, University of Southern Denmark, Odense, Denmark

${ }^{3}$ School of Public Health, University College Cork, Cork, Ireland

${ }^{4}$ Department of Public Health, Erasmus University Medical Centre, Rotterdam, The Netherlands

${ }^{5}$ Department of Clinical Research, University of Southern Denmark, Odense, Denmark ${ }^{6}$ Department of Public Health, University of Copenhagen, Copenhagen, Denmark ${ }^{7}$ Department of Psychology, University of Copenhagen, Copenhagen, Denmark

Correspondence to Kristina Karstad; kka@nrcwe.dk

\section{ABSTRACT}

Purpose Musculoskeletal disorders (MSDs), sickness absence and premature retirement are highly prevalent among eldercare workers. We conducted a prospective observational workplace study with the main purpose to investigate longitudinal associations between physical and psychosocial working conditions and occurrence of MSD and its consequences (pain-related interference with daily work activities and sickness absence) among Danish eldercare workers.

Participants At 20 Danish nursing homes, a total of 941 eldercare workers employed in day and evening shifts were invited to the study. Of those, 553 participated in the baseline measurements, and 441 completed the total period of 12 months follow-up.

Findings to date Data were collected from September 2013 to January 2016. Physical and psychosocial working conditions were assessed with multiple methods (observations, accelerometer measurements and work schedules), and multiple levels of information (nursing home, ward, resident and eldercare worker) were incorporated in the data collection. MSD and the consequences hereof were assessed monthly during a 1-year follow-up. Study participants and non-participants were comparable on most of the 27 sociodemographic, health and working condition characteristics at baseline. The exceptions were higher neck-shoulder pain intensity, less sickness absence, more exposure to negative behaviour from residents and a higher percentage of working day shifts and fewer evening shifts among participants compared with non-participants.

Future plans The first publications will report on the associations of physical and psychosocial working conditions with occurrence of MSD and its consequences. In addition, the cohort gives the opportunity to investigate the importance of organisational, management and team factors for distribution of physical work demands and development of MSD among the workers. This will provide important knowledge for future workplace interventions to reduce MSD and sickness absence.

\section{INTRODUCTION}

A high prevalence of musculoskeletal disorder (MSD) is reported in the general
Strengths and limitations of this study

- Comprehensive data collection with high completeness of data at 126 wards in 20 nursing homes including multiple independent methods at several levels of the organisation.

- Physical and psychosocial working conditions were assessed with workplace observations and work schedules, providing measures not relying on the eldercare workers' subjective perception and recall.

- Musculoskeletal disorders and the consequences hereof were assessed monthly during a 1-year follow-up using text messages.

- The lack of night-shift workers in the cohort and the differential distribution of shift work between participants and non-participants may limit the representativeness of the cohort for Danish eldercare workers.

- The strategy used to assess the eldercare worker's exposure does not incorporate specific information regarding the eldercare worker's individual working technique or their individual influence on the caring situation.

working population, ${ }^{1-3}$ but is a particular issue in specific occupational groups such as eldercare work, where annual prevalence is between $51 \%-71 \%$ for lower back pain (LBP) and $31 \%-52 \%$ for neck/shoulder pain (NSP). ${ }^{45}$ Accordingly, eldercare workers have high rates of sickness absence and premature retirement from the labour market, partly due to MSD. ${ }^{67}$ The high prevalence of MSD imposes major costs for the individuals afflicted, the workplaces and the society. ${ }^{89}$

Eldercare work involves manual handling activities such as lifting, repositioning and turning of residents and pushing and pulling of residents using different portable chairs. These tasks can be physically demanding for the eldercare worker, especially when performed in awkward body positions, and potentially increase the risk of 
MSD. ${ }^{10}{ }^{11}$ Moreover, the manual handling activities occur in a psychosocial context. The caring situation includes both verbal and physical interactions between the resident and the eldercare worker that may play a role in eldercare workers' risk of MSD and sickness absence, both independently of or in interaction with physical working conditions. ${ }^{12-14}$

However, the scientific documentation for a causal relation of physical and psychosocial working conditions with MSD is inconsistent. ${ }^{15-18}$ The existing research literature on the relation between physical and psychosocial work environment and MSD has been criticised for (1) a predominant use of self-reported exposure measurements that may be imprecise and biased, ${ }^{19-21}$ (2) lack of a multidisciplinary, multilevel approach that is of importance in understanding the interrelationships among exposures and the context in which they appear ${ }^{15} 22$ and (3) lack of repeated measurements of MSD during follow-up not sufficiently capturing the recurrent and fluctuating pattern of MSD. ${ }^{23}$

In order to address these shortcomings in the existing literature, the 'Danish Observational Study of Eldercare work and musculoskeletal disorderS (DOSES) ' was established. In DOSES, physical and psychosocial working conditions among eldercare workers were assessed with multiple methods (observations, accelerometer measurements and work schedules), not relying on the eldercare worker's own perception in a single questionnaire, and multiple levels of information (ie, nursing home, ward, resident and eldercare worker) were incorporated in the data collection. Furthermore, MSD and the consequences hereof were assessed monthly during a 1-year follow-up hereby allowing in-depth analysis of the fluctuating nature of MSD. The primary aim of DOSES is to examine the longitudinal associations between physical and psychosocial working conditions and occurrence of MSD (ie, LBP and NSP) and its consequences (ie, pain-related interference with daily work activities and sickness absence) among eldercare workers. Further, this cohort gives the opportunity to investigate the role of organisational structures in nursing homes for the physical and psychosocial working conditions and development of MSD, providing potentially important information for future workplace interventions to reduce MSD and sickness absence.

\section{COHORT DESCRIPTION}

DOSES is a prospective workplace observational study designed to examine longitudinal associations between physical and psychosocial working conditions and occurrence of MSD and its consequences among eldercare workers in Danish nursing homes. As exposures, we measured physical and psychosocial working conditions by workplace observations, diurnal accelerometer measurements and work schedules. As outcomes, we measured NSP and LBP and their consequences (ie, pain-related interference with daily work activities and sickness absence) every month during the follow-up period using text messages (SMS).

\section{Study participants}

Eligible study participants were eldercare workers between 18 and 65 years of age employed in Danish nursing homes more than 15 hours per week on day and evening shifts. Eldercare workers employed solely in night shift were not included in this cohort due to methodological and logistical reasons. Moreover, participants had to spend a minimum of $25 \%$ of their working time on tasks related to direct care of residents. This excluded administrative personnel, kitchen and cleaning personnel and most qualified nurses. Long-term sickness absence, pregnancy and not being permanently employed were further exclusion criteria for participation in the cohort.

In Denmark, eldercare workers usually have an education as nurses' aides, either as social and health service helpers (SHS helpers) or social and health service aides (SHS aides). SHS helpers have 14 months of training and are qualified for providing practical assistance, personal care and carry out activating and caring tasks for elderly people, handicapped and sick people in daily life. SHS aides have an additional 6 months of training and are additionally qualified for working in hospitals and psychiatry.

\section{Recruitment}

Eighty-three nursing homes located in Zeeland in the larger Copenhagen area in the eastern part of Denmark were invited to participate in the study. The nursing homes were purposively selected with the aims to include smaller and larger nursing homes and different care models. Twenty nursing homes with an average of 6.3 wards (SD 3.1), 79 residents (SD 28.9) and 70 eldercare workers (SD 27.7) employed more than 15 hours per week on day and evening shifts agreed to participate and were subsequently included in the study. Two nursing homes were private, and 18 were municipal nursing homes. Of the total 126 wards, 92 wards were primarily somatic units, 28 dementia units, 3 temporary/rehabilitation units and 3 psychiatric units for elderly people with special needs.

The nursing homes were invited to participate in the study by direct contact by email and follow-up phone calls to the management. If the management showed interest in participating in the study, a meeting between the management and other central persons (eg, health and safety and worker union representatives) at the nursing home and the research group was held to clarify the study details and further collaboration and participation in the study. If a nursing home chose to participate, a $30 \mathrm{~min}$ information meeting was arranged at the nursing home to inform the employees about the study. Prior to the information meeting, written information about the aim and activities of the research was distributed to all employees in a short information brochure. If necessary, more than one information meeting was arranged to ensure that as many employees as possible had the opportunity to participate in a meeting and get verbal information. At 


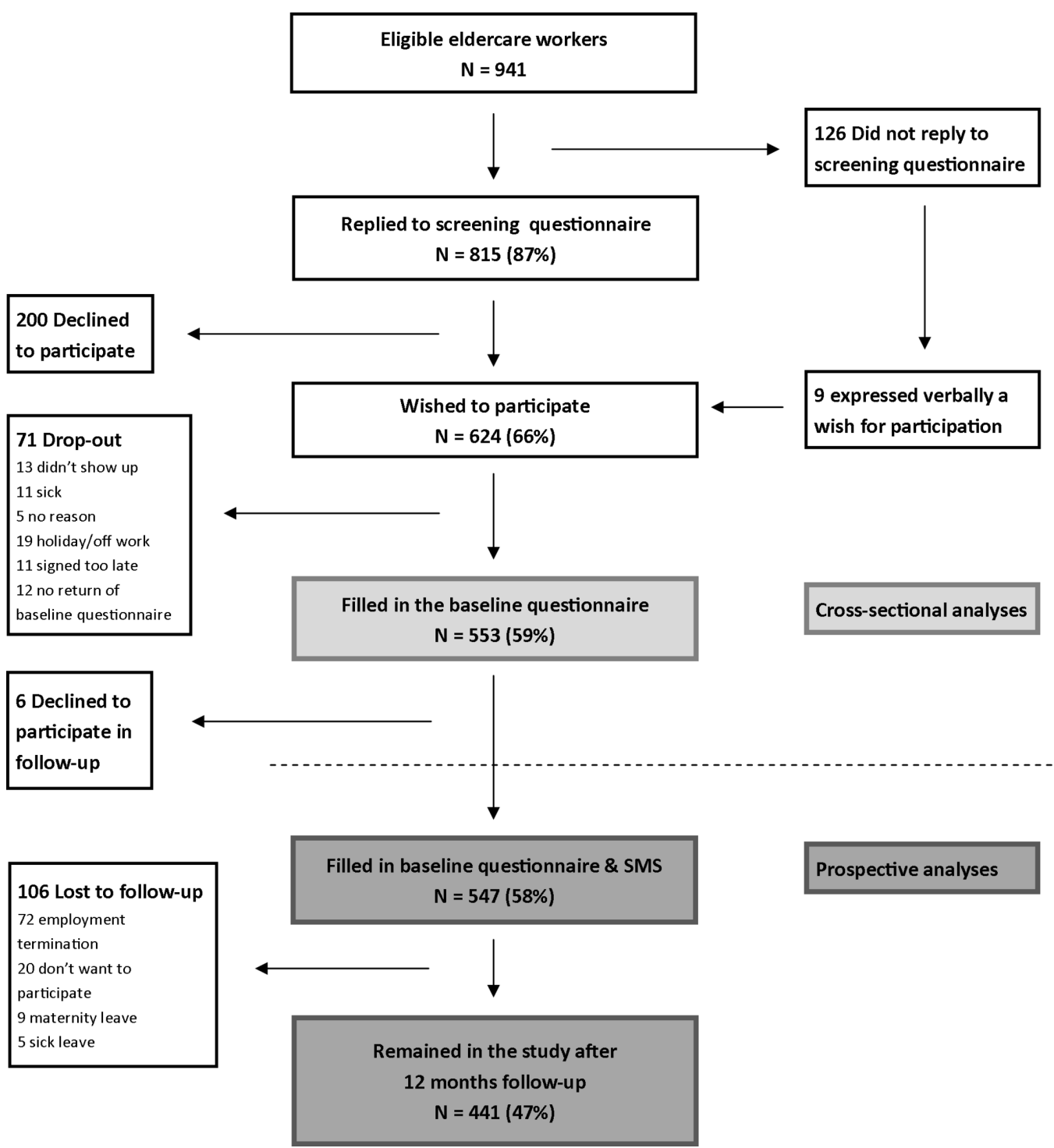

Figure 1 Flow chart-recruitment and dropout of participants throughout the reach, cross-sectional and prospective phases of DOSES. DOSES, Danish Observational Study of Eldercare work and musculoskeletal disorderS; SMS, text messages.

the end of the informal presentation, every employee was invited to participate in the study on a voluntary basis with the possibility of withdrawal at any time. They were asked to fill in a short screening questionnaire with the last question asking if they would like to participate in the study. Those who answered they wished to participate were invited to the individual measurements (ie, baseline questionnaire, accelerometer measurements, health and physical capacity measurements and answering SMS for 12 months). In order to participate, individuals were required to sign an informed consent when showing up for the individual measurements.

Figure 1 shows the flow chart of eldercare workers' participation throughout the study. From the 20 nursing homes included in the study, 941 eldercare workers were eligible for participation. Of those, 815 responded to the screening questionnaire. In total, 624 eldercare workers answered they wished to participate in the study in the screening questionnaire (nine expressed verbally a wish for participation without completing the screening questionnaire) and were invited to a 45 min session with administration of a questionnaire, health and capacity measurements and instructions on how to wear the accelerometers. Of these, 71 dropped out because they could not attend the session or did not return the baseline questionnaire, yielding a study population of 553 eldercare workers for the cross-sectional analyses. Finally, 547 participated in the 12 months follow-up by SMS, of which 441 remained in the study in the total period of 12 months.

\section{Data collection}

Data were collected from September 2013 until January 2016. At each participating nursing home, the baseline data collection took place over 1 to 2 weeks. Participants were then followed up for 12 months. The baseline data collection at the first nursing home started in September 2013 and the last in December 2014, resulting in the completion of follow-up in January 2016. 


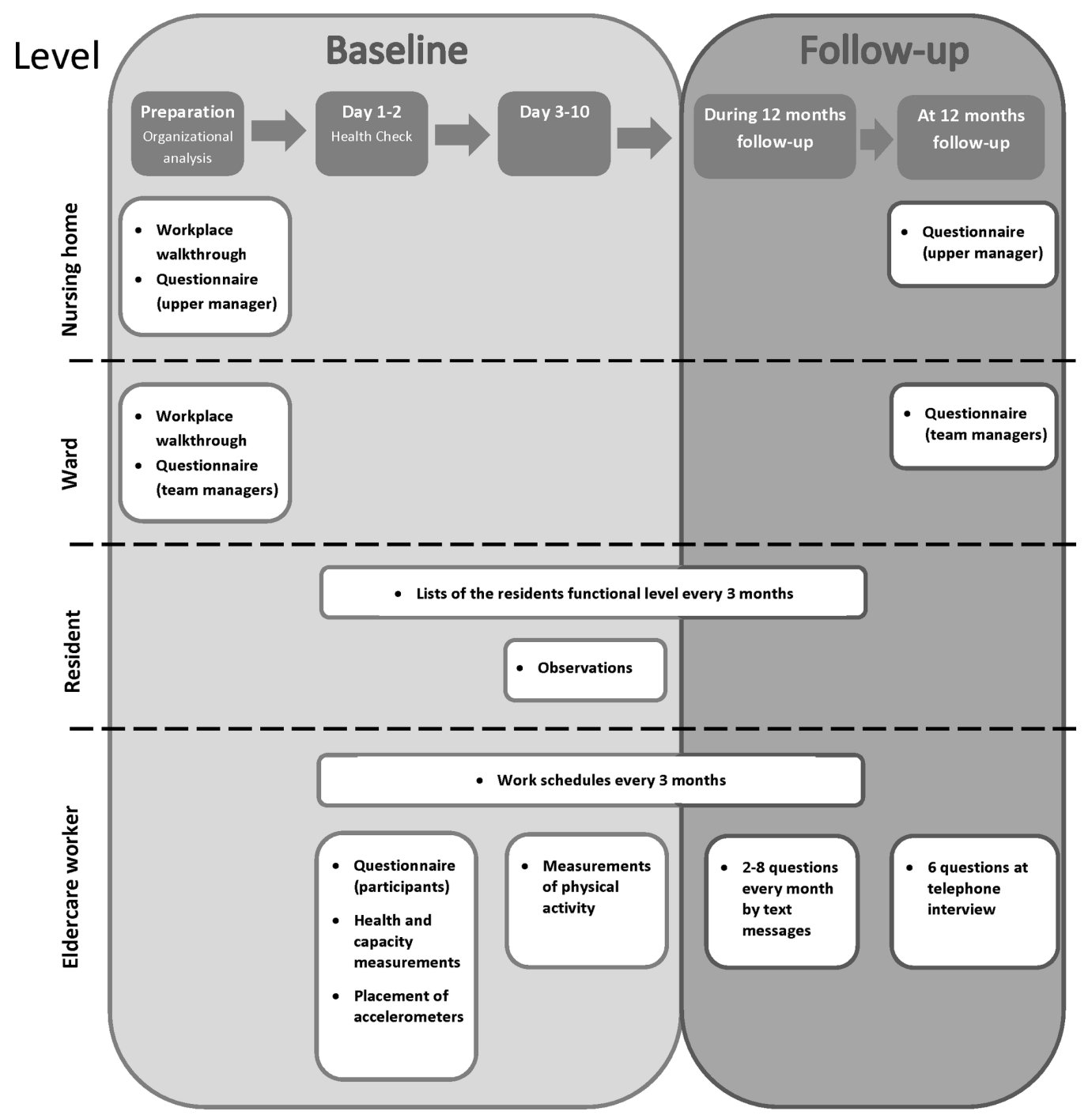

Figure 2 Data collection in DOSES. The data collection included information on four levels: (1) nursing home, (2) ward, (3) resident and (4) eldercare worker level. Baseline was divided into three parts. First, a preparation phase mainly used to gather information on nursing home and ward level. Next, 1-2 days with measures of each study participant during a 45 min session (health check session). Finally, 3-10 days with observations of physical and psychosocial working conditions. Follow-up data were collected on the eldercare worker level every month sending out 2-8 text messages and after 12 months an additional 6-question telephone interview. After 12 months, we did a follow-up at nursing home and ward level. At baseline and every 3 months during follow-up, we collected information from work schedules and on resident functional level. DOSES, Danish Observational Study of Eldercare work and musculoskeletal disorderS.

Data were collected at four levels: nursing home, ward, resident and eldercare worker level. Figure 2 presents all data collection in DOSES, and online supplementary appendix A presents a list of data items collected at baseline and during 12 months follow-up.

\section{Nursing home and ward level}

For investigation of the organisational structures that might influence the physical and psychosocial working conditions and the occurrence of MSD, information on nursing home and ward level was collected through a structured workplace walkthrough and questionnaires for the nursing home managers and team managers.

The walkthroughs were conducted at all 20 nursing homes and 126 wards at baseline. One researcher spent 1.5 hours at each nursing home following a structured protocol gathering information on the interior design (eg, flooring, space around bed and toilet and bath) and existence and accessibility of ergonomic equipment. ${ }^{24}$

At baseline and at 12 months follow-up, the nursing home manager and team managers of every nursing home answered a web-based questionnaire about formal and informal organisational structures at the nursing home and wards. If they did not reply within a week, they received a reminder by email followed by a phone call if not responding. The questionnaires at baseline and after 12 months were almost identical besides additional questions regarding major changes in organisational characteristics over the past year in the follow-up questionnaire. At baseline, 17 nursing home managers and all 42 team managers answered the questionnaire, 2 nursing 
home managers answered partly and 1 nursing home manager did not respond. At follow-up, all 20 nursing home managers but only 35 out of the 42 team managers answered the questionnaire, resulting in 15 wards with missing data regarding formal and informal organisational structures at ward level.

The specific data items collected at nursing home and ward level are listed in online supplementary appendix A.

\section{Resident level}

Direct care of residents is the core work in eldercare. The physical and psychosocial work exposures are therefore highly determined by the physical and psychosocial functional levels of the residents. Therefore, we conducted direct observations of the care work needed for each resident at baseline capturing all caring activities performed by the eldercare workers.

The real-time workplace observations were conducted at baseline by trained observers following a strict protocol that was developed based on previous workplace observational research studies. ${ }^{25-29}$ In a total of 18 individuals, either students or graduate students from sports science, physical activity and health science, public health science or occupational therapy were trained and worked as observers during the data collection period. The observations were performed using tablets in the program Noldus Observer XT pocket observer (Noldus, Wageningen, The Netherlands). Observations of direct caring activities included: (1) type of activity or routine (ie, morning routine, evening routine, personal care and feeding), (2) resident handling (ie, lifting, repositioning, turning, help with support stockings, push and pull resident in portable chair and kneeling), (3) if and what type of ergonomic devices used during the different resident handling activities, (4) help from colleague or others during resident handling activities, (5) residents' self-reliance during resident handling activity, (6) barriers for carrying out the work task (ie, interruptions and impediments) and (7) emotional demands from residents (ie, verbal aggression, physical aggression, verbal resistance, physical resistance, verbal support and physical support). The details of the observation instrument, training of the observers and inter-rater reliability of the observational instrument is described elsewhere. ${ }^{30}$ The inter-rater agreement of the observation instrument was shown to be good.

A secondary data analysis of a previous observational study in Danish nursing homes by Jakobsen $e t a l^{26}$ showed that approximately $71 \%$ of all resident handling activities occurred during a period of 4 hours in the morning and $4-5$ hours in the evening. To save resources, we therefore limited the observations to these two time periods. Both eldercare workers and residents had the right to deny observation or parts of observation. A total of 4716 (2673 day shift and 2043 evening shift) observation sequences of direct caring activities involving both residents and care workers were performed at the 20 nursing homes. We performed observations on 1279 residents $(88 \%$ of total number of residents) during day shift and 1148 residents (79\% of total number of residents) during evening shift.

To assess changes in residents' functional levels after baseline, we collected during follow-up from each nursing home documentation on residents' current physical and psychosocial functional levels and body weight. Physical functional level was ranked based on the need for physical assistance as either 'light', 'moderate', 'extensive' or 'completely'. Psychosocial functional level was ranked based on residents' behaviour as either 'predominantly neutral', 'predominantly positive/appreciatively', 'predominantly resistance' or 'predominantly aggressive'. These lists were collected at baseline and every 3 months throughout the entire 1-year follow-up period.

\section{Eldercare worker level}

Information on sociodemographics, lifestyle, health and work-related factors was collected by five different methods: (1) a structured self-administered questionnaire, (2) technical measures of health and physical capacity, (3) accelerometer measurements of physical activity at work and leisure, (4) work schedules and (5) SMS. The full list of items collected at eldercare worker level is listed in online supplementary appendix A.

A computer-based structured questionnaire was filled in at baseline by each participant when attending a 45 min long health check session held at the respective workplaces. Research personnel were available in case the participants had problems understanding the questions. The questionnaire included questions on sociodemographics, lifestyle and health-related behaviour, health and morbidity, physical work environment and psychosocial work environment. After 12 months, the six questions from the baseline questionnaire regarding work ability, general health, need for recovery, mental health, MSD in other body regions than LBP and NSP and medicine use were assessed with telephone interview.

Measures of health and physical capacity (eg, height, body weight, body mass index (BMI) and blood pressure) of the participants were collected at the health check session. The measurements were performed by trained clinical personnel.

Information about physical activity types (eg, walking, running and cycling), body postures (eg, sitting and standing) and movements (eg, forward bending of the back and arm elevation) during both work and leisure time was attained from ActiGraph GT3X+ accelerometers (ActiGraph, Florida, United States). A validated software program (Acti4) was applied for analysing the accelerometer data with very high sensitivity and specificity. ${ }^{31}$ At the health check session, participants were asked to wear three accelerometers (on the thigh, upper back and dominant arm) for a minimum of four consecutive days including at least two working days. Participants allergic to patches were excluded from wearing the accelerometers. In total, 452 participants $(82 \%)$ provided data from the accelerometer measurements. 


\section{Main physical and psychosocial work exposures}

Work schedules were collected from all nursing homes for all eligible workers (regardless of the acceptance of participation in the individual measurements) every 3 months.

The work schedules contained standardised information about the specific residents each eldercare worker was assigned to for giving direct care with specification of the respective days within a 3-week period. The work schedules were filled in by the eldercare workers every morning during planning of the daily work. The eldercare workers were instructed to point out if anything according to the plan changed during the shift. The schedules were collected at baseline and every 3 months throughout the entire 1-year follow-up period. If the team manager did not send the work schedules after several reminders to the research personnel or if an eldercare worker participating in the study did not provide all necessary information, research personnel phoned the eldercare worker and collected the work schedule information from the last 4 days at work.

The physical and psychosocial work exposures of each individual eldercare worker were estimated by combining data from the resident level and the eldercare worker level. Observations of the caring activities required for each respective resident were merged with the work schedules (ie, distribution of the residents between eldercare workers). Based on the number of shifts reported in the work schedules, the summed number and duration of observed physical and psychosocial working exposures for each eldercare worker were calculated as an exposure per shift. The main physical exposures were: lifting, repositioning and turning of the resident (with information regarding use of assistive device, residents' self-reliance and assistance from colleague), pulling a support stocking up or down, push/pull resident in portable chair and squatting. The main psychosocial exposures were: appreciation from resident, resistance from resident, aggression from resident, negative behaviour from resident (resistance and aggression from resident), interruptions and impediments during care giving.

\section{Main outcomes}

An SMS method (a Danish commercial system, http:// www.sms-track.com/Default.aspx) was applied for retrieving monthly follow-up on occurrence of MSD and its consequences (pain-related interference with daily work activities, general sickness absence and sickness absence due to MSD). Recent studies have shown that monthly SMS during a 1-year follow-up period to assess information on MSD and its consequences are an appropriate method for limiting recall bias and capturing the recurrent and fluctuating pattern of MSD. ${ }^{23}{ }^{32}$ The participants provided their mobile phone numbers to the research personnel at the health check session.

Every fourth week during the 12 months follow-up period, the participants received up to 5 SMS (depending on their answers) with questions on their mobile phone.
Five times during the 12 months, every twelfth week, two additional SMS regarding sickness absence and three additional SMS regarding physical and psychosocial working conditions were applied. The participants received the questions on Mondays, with a reminder on Wednesdays (if no response was received). If they still had not answered by the end of the week, research personnel collected their answers by calling them on their mobile phone.

The following questions were posed by the SMS method every month:

LBP

In the last 4 weeks, how many days did you have pain in your low back region? (Answer from 0 to 28). If the participant replied one or more, the following additional question was asked "On a scale from 0 to 10 , what was the worst pain you have experienced in your low back within the past 4 weeks?" ( $0=$ no pain, $10=$ worst possible pain) NSP

In the last 4 weeks, how many days did you have pain in your neck/shoulder region? (Answer from 0 to 28) and if one or more was replied, the following question was asked "On a scale from 0 to 10 , what was the worst pain you have experienced in your neck/shoulders within the past 4 weeks?" ( $0=$ no pain, $10=$ worst possible pain).

Pain-related interference with daily work activities

If the participants answered one or more in either the question on LBP or NSP the following question was asked "Within the past 4 weeks, how many days did pain in your low back and/or neck/shoulders made it difficult to perform your normal work (ie, interfered/ limited your performance at work)?" (Answer from 0 to 28).

The following questions were posed by the SMS method every 3 months:

Sickness absence

How many days with sickness absence have you had within the past 12 weeks? (Answer from 0 to 84). If the participant replied one or more, the following additional question was asked "How many of these days with sickness absence were due to pain in your low back and/or neck/shoulders?" (Answer from 0 to 84).

\section{Characteristics of study participants}

Table 1 shows baseline characteristics of the study participants, estimated exposures from observations and work schedules and NSP, LBP, pain-related interference with work and sickness absence during the 12 months follow-up. The participants were primarily women with an average age of 46 years. They were slightly overweight with an average BMI of $26 \mathrm{~kg} / \mathrm{m}^{2}, 35 \%$ were current smokers and $16 \%$ reported reduced self-rated health. Moreover, the participants reported on average the physical and emotional exertion during work on a scale from 0 to 10 to be 6.6. With respect to employment, $39 \%$ were employed as SHS aides, $47 \%$ as SHS helpers and $14 \%$ as 
Table 1 Self-reported baseline characteristics and observed physical and psychosocial working conditions per shift for participants and non-participants in DOSES and pain and consequences during 12 months follow-up for participants only

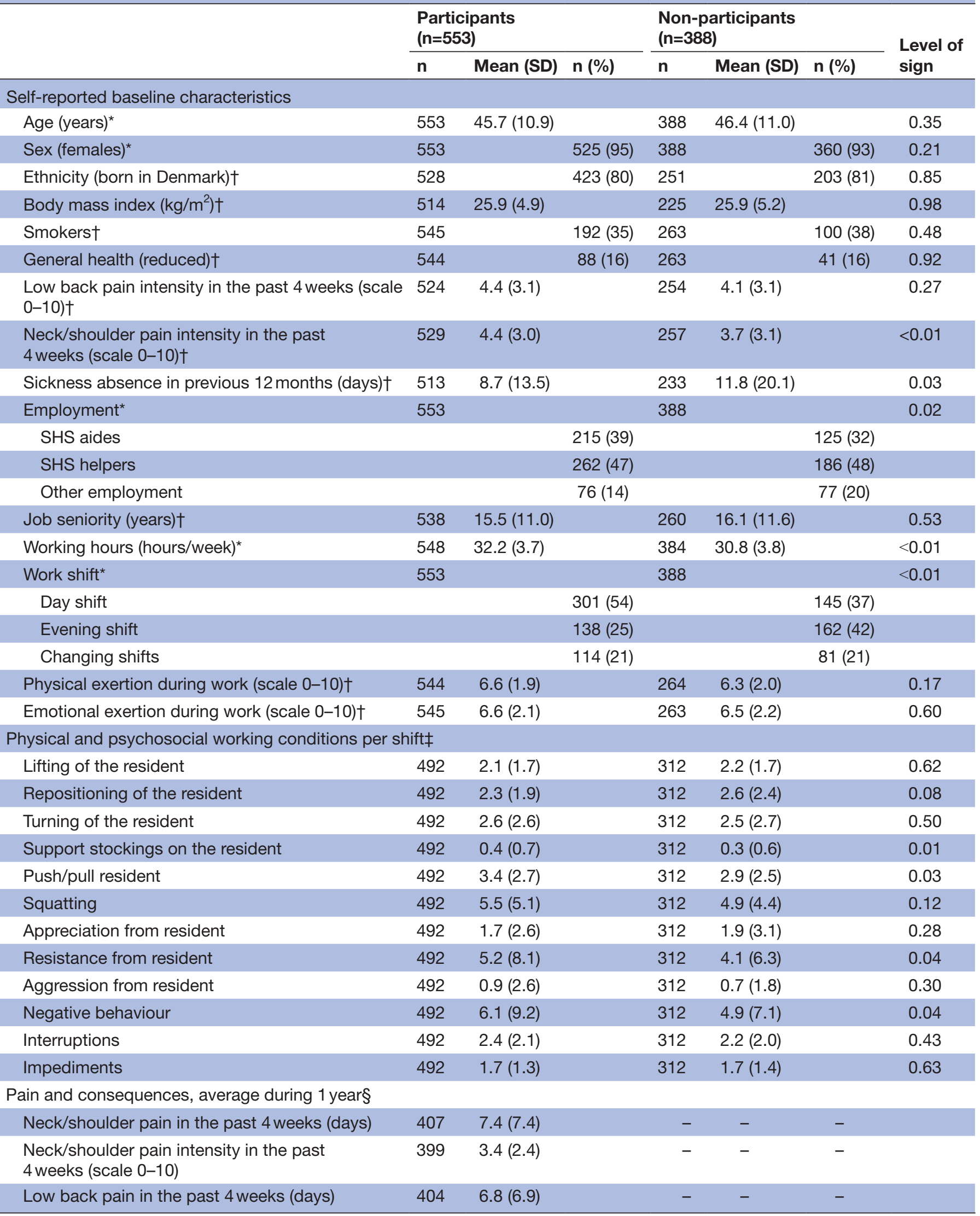




\begin{tabular}{|c|c|c|c|c|c|c|c|}
\hline & \multicolumn{3}{|c|}{$\begin{array}{l}\text { Participants } \\
(\mathrm{n}=553)\end{array}$} & \multicolumn{3}{|c|}{$\begin{array}{l}\text { Non-participants } \\
(\mathrm{n}=388)\end{array}$} & \multirow{2}{*}{$\begin{array}{l}\text { Level of } \\
\text { sign }\end{array}$} \\
\hline & $\mathbf{n}$ & Mean (SD) & n (\%) & $\mathrm{n}$ & Mean (SD) & n (\%) & \\
\hline $\begin{array}{l}\text { Pain-related interference in the past } 4 \text { weeks } \\
\text { (days) }\end{array}$ & 389 & $4.8(5.7)$ & & - & - & - & \\
\hline $\begin{array}{l}\text { Sickness absence due to lower back or neck/ } \\
\text { shoulder pain in the past } 12 \text { weeks (days) }\end{array}$ & 417 & $1.0(3.3)$ & & - & - & - & \\
\hline
\end{tabular}

Participants ( $n=553$ ) filled in the baseline questionnaire and comprise the study population for the cross-sectional analyses. The nonparticipants $(n=388)$ declined to participate or dropped out before responding to the baseline questionnaire.

${ }^{*}$ Assessed through payroll.

†Self-reported information from screening questionnaires.

łEstimated exposure from observation of residents and work schedules.

§Assessed through SMS during 12 months follow-up (participants with a minimum 80\% responses).

DOSES, Danish Observational Study of Eldercare work and musculoskeletal disorderS; SHS, social and health service; SMS, text messages.

other employment. More than half (54\%) were hired in day shift, $25 \%$ in evening shift and $21 \%$ in changing shifts. Average job seniority was 16 years, and average working hours per week was 32 .

At baseline, 492 out of the 553 participants (89\%) had filled in the work schedules. The participants performed on average two lifts, two repositioning and three turns of the residents per shift. On average, they also pushed or pulled residents in portable chairs three times per shift. With respect to the interaction with the residents, on average, the participants received appreciation from the residents two times and met negative behaviour six times per shift. On average, the participants got interrupted two times and experienced impediments two times per shift.

Regarding the questions on MSD and pain-related interference with work, more than $70 \%$ of the participants being included in the follow-up responded to at least 12 out of the total 14 questions posted on SMS during the 1-year period. Only $0.5 \%$ of the participants did not respond to any questions regarding MSD and pain-related interference with work. On average, NSP and LBP intensity in the last 4 weeks on a scale from 0 to 10 were 3.4 for both body sites. Number of days in the past 4 weeks with NSP, LBP and pain-related interference with work were on average 7,7 and 5 days, respectively. Regarding the questions on sickness absence, the percentage of participants responding to at least 4 out of the total 5 questions sent out during the 1-year long follow-up period was $76 \%$. The percentage of participants who did not respond to any questions regarding sickness absence was $2.4 \%$. On average, the participants reported 2 days of sickness absence per 12 weeks, of which 1 day was due to NSP or LBP.

In order to describe the representativeness of the participants at baseline, we investigated for potential differences between the participants and non-participants in self-reported baseline characteristics and observed physical and psychosocial working conditions per work shift. We found no differences in 18 out of the 27 tested baseline characteristics and observed physical and psychosocial working conditions between the participants and non-participants (table 1). Four (ie, employment, working hours, number of support stockings handled per shift and number of pushing and pulling residents in portable chairs per shift) showed a statistically significant difference between participants and non-participants, but the differences were small, and therefore considered not to be of work-related or clinical importance. However, five baseline characteristics and observed physical and psychosocial working conditions were statistically significantly different at a magnitude considered to be of importance between the two groups. The participants reported higher NSP intensity in the past 4 weeks, fewer days with sickness absence in the past 12 months and a higher percentage of participants worked day shifts and fewer evening shifts compared with non-participants. Moreover, the participants experienced more negative behaviour per shift as a consequence of more resistance from residents compared with non-participants.

\section{FINDINGS TO DATE}

The first manuscripts to peer-reviewed journals on this cohort are expected to be submitted in 2018. These manuscripts will report on the main purpose of the cohort-investigating associations between physical and psychosocial working conditions and occurrence of MSD and its consequences among eldercare workers in Danish nursing homes.

\section{FUTURE DIRECTIONS}

The cohort offers several possibilities for specific analyses and linked follow-up studies. For example, we will start 
a new project investigating the factors at organisational, management and department level of nursing homes that determines the physical workload of eldercare workers. Furthermore, we will investigate the determinants of specific trajectories of MSD.

The DOSES cohort is exceptional with the frequent assessment of MSD by monthly SMS during 12 months and the participants' high response rates. Therefore, we plan to investigate the course of MSD more in detail and the fluctuating nature of MSD using latent class analyses.

The DOSES cohort includes a 1-year follow-up; however, there are possibilities for future data collection through national registers (eg, employment and health registers) as all participants in DOSES have unique Danish civil registration numbers.

\section{STRENGTHS AND LIMITATIONS}

The major strength of DOSES is the comprehensive design incorporating data assessed with multiple methods at multiple levels. Completeness of data at baseline was high and attrition during follow-up low. The DOSES cohort includes sampled data from 20 nursing homes and 126 wards of different sizes and types representing a broad spectrum of nursing homes in Denmark. This design gives unique opportunity to conduct multilevel analyses and disentangle the effects of individual wards and nursing homes from overall effects that working conditions and work organisational factors may have on the onset and aggravation of MSD. Furthermore, the design provides the opportunity for investigating independent and combined associations of different measures for physical and psychosocial working conditions and MSD. All data were collected in situ augmenting the external validity.

The physical and psychosocial working conditions were assessed with a new strategy (ie, merging information of the residents' need for care from observations and information of the distribution of the residents between the eldercare workers from work schedules) and methods (observations, accelerometer measurements and work schedules), providing measures not solely relying on the eldercare workers own perception and recall, hereby avoiding common bias in this type of research. Further, we collected information from participants' work schedule and changes in residents' physical and psychosocial functional levels every 3 months after baseline, allowing us to take changes in exposure during follow-up into account.

The repeated measurements every month during the follow-up period of LBP, NSP and their consequences will improve the understanding of the recurrent and fluctuating patterns of MSD. Furthermore, it will enable the use of analytical approaches that can distinguish shortterm effects (exposure events that trigger onset of an MSD episode) from long-term effects due to cumulative exposure.

The eldercare worker's individual work exposure was not assessed by the eldercare workers' individual work performance, but by the residents' need which is indicative of the care requirements put on the worker. This approach is a strength of the study because we directly assess the work task and its objective requirements, the entity we are interested in. However, this approach also has limitations because the work task is likely to be influenced by the individual eldercare workers' working technique which may also influence the caring situation. However, individual working techniques may become apparent through the diurnal accelerometer measurements conducted and will allow for adjustment for this potential confounder.

In terms of the representativeness of the study population of DOSES, $59 \%$ of all the eligible workers participated in the baseline measurements. Compared with the screened workers not participating in this cohort, the participants had higher NSP intensity, less sickness absence, more negative behaviour and resistance from residents per shift and a higher percentage working day shifts and fewer evening shifts among the participants. Further, this cohort does not include night-shift workers. When considering size and importance of the differences between participants and non-participants, the DOSES cohort is likely representative for the targeted population of Danish eldercare workers, however, with the exception of the distribution of work shift.

Acknowledgements The authors wish to thank the entire DOSES research group and personnel who contributed to the data collection, especially Dorte Ekner and Rikke Berner Rasmussen, and the 20 nursing homes that participated in DOSES. We also gratefully acknowledge the group of data managers at the National Research Centre for the Working Environment for their tremendous work in handling the excessive amounts of data.

Contributors $\mathrm{AH}$ and RR conceived the general research idea of the DOSES study and wrote the initial research proposal. KK, AFBJ, BAG, AB, KS, RR and AH contributed through discussions and meetings to the design of DOSES and the design of this specific paper. KK was responsible for drafting the paper especially with support from $\mathrm{AH}$ and performed the statistical analyses of the present paper. AFBJ, BAG, AB, KS, RR and AH have read, commented and critically revised the draft version and approved the final version of the manuscript. All authors have agreed to be accountable for all aspects of the work.

Funding The study was financed by a grant from the Danish government. Competing interests None declared.

Patient consent Obtained.

Ethics approval DOSES received ethical approval from the Danish Data Protection Agency and the Ethics Committee for the regional capital of Denmark (H-4-2013-028).

Provenance and peer review Not commissioned; externally peer reviewed.

Data sharing statement Completely anonymised data can be obtained by contacting the corresponding author.

Author note We welcome applications from external researchers to cooperation on the DOSES cohort. Inquiries should be made to the DOSES principal investigators via Professor Andreas Holtermann (aho@nrcwe.dk).

Open Access This is an Open Access article distributed in accordance with the Creative Commons Attribution Non Commercial (CC BY-NC 4.0) license, which permits others to distribute, remix, adapt, build upon this work non-commercially, and license their derivative works on different terms, provided the original work is properly cited and the use is non-commercial. See: http://creativecommons.org/ licenses/by-nc/4.0/

(c) Article author(s) (or their employer(s) unless otherwise stated in the text of the article) 2018. All rights reserved. No commercial use is permitted unless otherwise expressly granted. 


\section{REFERENCES}

1. Bevan S, Quadrello T, McGee R, et al. Fit For Work? Musculoskeletal disorder and the European workforce. London: The Work Foundation, 2009.

2. Det Nationale Forskningscenter for Arbejdsmiljø (NFA). Arbejdsmiljø og helbred I Danmark 2012 - Resumé og resultater. København: Det Nationale Forskningscenter for Arbejdsmiljø (NFA), 2013.

3. Global Burden of Disease Study 2013 Collaborators. Global, regional, and national incidence, prevalence, and years lived with disability for 301 acute and chronic diseases and injuries in 188 countries, 19902013: a systematic analysis for the Global Burden of Disease Study 2013. Lancet 2015;386:743-800.

4. Davis KG, Kotowski SE. Prevalence of musculoskeletal disorders for nurses in hospitals, long-term care facilities, and home health care: a comprehensive review. Hum Factors 2015;57:754-92.

5. Luime JJ, Kuiper JI, Koes BW, et al. Work-related risk factors for the incidence and recurrence of shoulder and neck complaints among nursing-home and elderly-care workers. Scand J Work Environ Health 2004;30:279-86.

6. Andersen LL, Clausen T, Mortensen OS, et al. A prospective cohort study on musculoskeletal risk factors for long-term sickness absence among healthcare workers in eldercare. Int Arch Occup Environ Health 2012;85:615-22

7. Jensen LD, Ryom PK, Christensen MV, et al. Differences in risk factors for voluntary early retirement and disability pension: a 15-year follow-up in a cohort of nurses' aides. BMJ Open 2012;2:e000991.

8. Mäntyselkä PT, Kumpusalo EA, Ahonen RS, et al. Direct and indirect costs of managing patients with musculoskeletal pain-challenge for health care. Eur J Pain 2002;6:141-8.

9. Saarni SI, Härkänen T, Sintonen H, et al. The impact of 29 chronic conditions on health-related quality of life: a general population survey in Finland using 15D and EQ-5D. Qual Life Res 2006;15:1403-14.

10. Lagerström M, Hansson T, Hagberg M. Work-related low-back problems in nursing. Scand J Work Environ Health 1998;24:449-64.

11. Trinkoff AM, Lipscomb JA, Geiger-Brown J, et al. Perceived physical demands and reported musculoskeletal problems in registered nurses. Am J Prev Med 2003;24:270-5.

12. Aagestad $C$, Tyssen $R$, Johannessen HA, et al. Psychosocial and organizational risk factors for doctor-certified sick leave: a prospective study of female health and social workers in Norway. BMC Public Health 2014;14:1016.

13. Miranda H, Punnett L, Gore RJ, et al. Musculoskeletal pain and reported workplace assault: a prospective study of clinical staff in nursing homes. Hum Factors 2014;56:215-27.

14. Miranda H, Punnett L, Gore R, et al. Violence at the workplace increases the risk of musculoskeletal pain among nursing home workers. Occup Environ Med 2011;68:52-7.

15. da Costa BR, Vieira ER. Risk factors for work-related musculoskeletal disorders: a systematic review of recent longitudinal studies. Am J Ind Med 2010;53:285-323.

16. Heneweer H, Staes F, Aufdemkampe G, et al. Physical activity and low back pain: a systematic review of recent literature. Eur Spine $J$ 2011;20:826-45.
17. Kwon BK, Roffey DM, Bishop PB, et al. Systematic review: occupational physical activity and low back pain. Occup Med 2011;61:541-8.

18. Swedish Council on Health Technology Assessment. Occupational exposures and back disorders. stockholm: Swedish council on health technology assessment (SBU). 2014 http://www.ncbi.nlm.nih. gov/books/NBK316437/ (accessed 13 Jan 2017).

19. Kwak L, Proper KI, Hagströmer M, et al. The repeatability and validity of questionnaires assessing occupational physical activity--a systematic review. Scand J Work Environ Health 2011;37:6-29.

20. Gupta N, Heiden M, Mathiassen SE, et al. Prediction of objectively measured physical activity and sedentariness among blue-collar workers using survey questionnaires. Scand $J$ Work Environ Health 2016;42.

21. Koch M, Lunde LK, Gjulem T, et al. Validity of questionnaire and representativeness of objective methods for measurements of mechanical exposures in construction and health care work. PLoS One 2016;11:e0162881.

22. Hagberg M, Punnett L, Bergqvist U, et al. Consensus report. Scand J Work Environ Health 2001;27:354-7.

23. Kongsted A, Leboeuf-Yde C. The Nordic back pain subpopulation program--individual patterns of low back pain established by means of text messaging: a longitudinal pilot study. Chiropr Osteopat 2009;17:11.

24. Koppelaar E, Knibbe JJ, Miedema HS, et al. The influence of individual and organisational factors on nurses' behaviour to use lifting devices in healthcare. Appl Ergon 2013;44:532-7.

25. Jakobsen LM, Jorgensen AF, Thomsen BL, et al. Emotion work within eldercare and depressive symptoms: a cross-sectional multilevel study assessing the association between externally observed emotion work and self-reported depressive symptoms among Danish eldercare workers. Int J Nurs Stud 2016;62:183-92.

26. Jakobsen LM, Jorgensen AF, Thomsen BL, et al. A multilevel study on the association of observer-assessed working conditions with depressive symptoms among female eldercare workers from 56 work units in 10 care homes in Denmark. BMJ Open 2015;5:e008713.

27. Park JK, Boyer J, Tessler J, et al. Inter-rater reliability of PATH observations for assessment of ergonomic risk factors in hospital work. Ergonomics 2009;52:820-9.

28. Johnsson C, Kjellberg K, Kjellberg A, et al. A direct observation instrument for assessment of nurses' patient transfer technique (DINO). Appl Ergon 2004;35:591-601.

29. Warming S, Juul-Kristensen B, Ebbehøj NE, et al. An observation instrument for the description and evaluation of patient transfer technique. Appl Ergon 2004;35:603-14.

30. Karstad K, Rugulies R, Skotte J, et al. Inter-rater reliability of direct observations of the physical and psychosocial working conditions in eldercare: An evaluation in the DOSES project. Appl Ergon 2018;69:93-103.

31. Skotte J, Korshøj M, Kristiansen J, et al. Detection of physical activity types using triaxial accelerometers. J Phys Act Health 2014;11:76-84.

32. Johansen B, Wedderkopp N. Comparison between data obtained through real-time data capture by SMS and a retrospective telephone interview. Chiropr Osteopat 2010;10. 